\title{
Diyabetik Polinöropatiyi Predikte Eden Bağımsız Klinik ve Demografik Faktörler
}

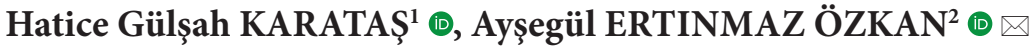 \\ ${ }^{1}$ Karabük Üniversitesi Tip Fakültesi, Fiziksel Tip ve Rehabilitasyon Anabilim Dalı, Karabük, Türkiye \\ ${ }^{2}$ Karabük Üniversitesi Tıp Fakültesi, İç Hastalıkları Anabilim Dalı, Karabük, Türkiye
}

Bu makaleye yapılacak atıf: Karataş HG, Ertınmaz Özkan A. Diyabetik Polinöropatiyi Predikte Eden Bağımsız Klinik ve Demografik Faktörler. Türk Diyab Obez 2020;1: 11-15.

\begin{abstract}
ÖZET
Amaç: Diabetes Mellitus (DM) hastalarındaki diyabetik periferik polinöropatiler (DNP) yaşam kalitesini olumsuz etkileyen önemli bir komplikasyondur. İç Hastalıkları ve Fiziksel Tıp ve Rehabilitasyon (FTR) polikliniğinde DNP açısından yüksek riskli hastaları öngörmek, daha hızlı ve doğru şekilde DNP tanısı koymaya ve tanının atlanmasının önüne geçmeye yardımcı olacaktır.

Gereç ve Yöntemler: Ocak 2018-Ağustos 2019 tarihleri arasında Karabük Üniversitesi Eğitim ve Araştırma Hastanesi FTR ve İç Hastalıkları polikliniğine herhangi bir nedenle başvuran 173 erkek ve 226 kadın olmak üzere toplam 399 DM tanılı hasta dahil edildi. DNP tanısı LANSS ölçeği (Leeds Assessment of Neuropathic Symptoms and Signs) ile konuldu ve sonrasında hastalar polinöropatik olan (DNP+) ve olmayanlar (DNP-) olarak iki gruba ayırıldı. Gruplar arasındaki demografik veriler, VKİ (vücut kütle indeksi), HbA1c düzeyi, DM süreleri, oral antidiyabetik (OAD) ve/veya insülin kullanımları karşılaştırıldı. DNP için bağımsız prediktörler lojistik regresyon analiziyle incelendi.

Bulgular: Hastaların \%38,6'sında DNP mevcuttu. Ortalama yaş, DM süresi ve VKİ DNP+ grupta DNP-'lere kıyasla anlamlı derecede yüksekti [sirasiyla; (62,4 $\pm 11,1$ ve 59,3 $\pm 12,4$ ay, $\mathrm{p}=0,014),(72,7 \pm 29,9$ ve $54,0 \pm 26,5$ ay, $\mathrm{p}<0,001),(33,6 \pm 6,3$ ve $31,3 \pm 6,5, \mathrm{p}=0,001)$ ]. $\mathrm{DNP}, \mathrm{HbA1c}$ değeri $>7$ olanlarda $\leq 7$ olanlara göre daha sı görülmekteydi $(\mathrm{p}=0,026)$. OAD, insülin kullanımları ve HbAlc düzeyleri gruplar arasında benzerdi $(\mathrm{p}=0,107, \mathrm{p}=0,075$ ve 0,232$)$. Lojistik regresyon analizinde, HbAlc düzeyi, cinsiyet ve insülin ya da oral antidiyabetik kullanımları ile DNP arasında bağımsız bir ilişki saptanmazken $(\mathrm{P}>0,05)$, hastalık süresinin uzun ( $>61$ ay) olması, ileri yaş ( $>60,5$ yaş) ve obezitenin DNP için bağımsız prediktörler oldukları saptandı [sırasıyla; Odds ratio (OR): 2,78 (\%95 Güven Aralığı (CI); $1,832-4,228$, p <0,001), OR: 1,62, \%95CI; 1,053 - 2,493), $\mathrm{P}=0,028$ ve OR: 1,78, \%95CI; 1,143 - 2,789), $\mathrm{P}=0,011)$ ].
\end{abstract}

Sonuç: DM'li hastalarda ileri yaş, beş yıldan uzun hastalık süresi ve obezitenin DNP için bağımsız klinik parametreler oldukları saptanmıştır. Günlük pratikte DNP’yi predikte edebilen bu kriterler ucuz ve kolay uygulanabilirliği nedeniyle göz önünde tutulmalıdır.

Anahtar Sözcükler: Diabetes mellitus, HbA1c, Obezite, Polinöropati, Süre

\section{Independent Clinical and Demographic Factors Predicting Diabetic Polyneuropathy}

\begin{abstract}
Aim: Diabetic peripheral polyneuropathies (DPP) in patients with diabetes mellitus (DM) are important complications that adversely affect the quality of life. In the Internal Medicine and Physical Medicine and Rehabilitation (PMR) outpatient clinic, predicting high-risk patients for DPP will help to diagnose it more quickly and accurately while preventing missed diagnosis.

Material and Methods: A total of 399 DM patients, 173 males and 226 females, were admitted to the PMR and Internal Medicine outpatient clinic of Karabuk University Training and Research Hospital between January 2018 and August 2019 for various reasons. The diagnosis of DPP was made using the LANSS scale (Leeds Assessment of Neuropathic Symptoms and Signs), and the patients were then divided into two groups as polyneuropathic (DPP +) and non-polyneuropathic (DPP - ). Demographic data, BMI, HbA1c level, DM duration, oral antidiabetic (OAD) and / or insulin use were all compared between the groups. Independent predictors for DPP were examined by logistic regression analysis.
\end{abstract}

ORCID: Hatice Gülşah Karataş / 0000-0001-5007-1008, Ayşegül Ertınmaz Özkan / 0000-0002-3273-1305 
Results: DPP was present in $38.6 \%$ of the patients. Mean age, duration of DM and BMI were significantly higher in DPP + group compared to DNP-[[respectively; $(62.47 \pm 11.17$ and $59.35 \pm 12.48$ months, $\mathrm{p}=0.014),(72.73 \pm 29.91$ and $54.04 \pm 26.53$ months, $\mathrm{p}<0.001),(33.69 \pm 6.38$ and $31.39 \pm 6.52, \mathrm{p}=0.001)]$. DPP was more common in patients with a HbA1clevel of $>7$ than those with $\leq 7$ ( $\mathrm{p}$ $=0.02)$. OAD, insulin use and HbA1c levels were similar between the groups $(\mathrm{p}=0.10, \mathrm{p}=0.07$ and 0.23$)$. In logistic regression analysis, there was no independent correlation between HbA1c level, gender, insulin or oral antidiabetic use and DPP ( $p>0.05$ ), while long disease duration (>61 months), advanced age and obesity were found to be independent predictors of DPP [respectively; Hazard ratio (HR): 2.78 (95\% Confidence Interval (CI); 1.832-4.228, p<0.001), HR: 1.62, 95\% Cl; 1.053-2.493), p=0.028 and HR: 1.78, 95\% Cl; 1.143-2.789), $\mathrm{p}=0.011)]$.

Conclusion: In patients with DM, elderly age, duration of the disease for more than five years and obesity were found to be independent clinical parameters for DPP. These criteria, which can predict DPP in daily practice, should be considered because of their cheapness and easy applicability.

Key Words: Diabetes mellitus, HbA1c, Obesity, Polyneuropathy, Duration

\section{GíRiş}

Diabetes Mellitus (DM) anormal karbonhidrat metabolizması ile karakterize bir hastalık olup, dünya çapında kronik hastalıklara bağlı morbidite ve mortalitenin en sık nedenidir (1). IDF verilerine göre 2015 yllında dünya genelinde 415 milyon DM hastası mevcuttur ve 2040 yilında bu rakamın 642 milyona yükselmesi beklenmektedir (2). DM'ye bağlı mortalite ve morbiditelerin en sık nedeni vasküler (mikro-makro vasküler) komplikasyonlardır (3). DM’ye bağlı en sık gelişen kronik mikrovasküler komplikasyon diyabetik polinöropatidir (DNP) (4). DNP'nin en yaygın şekli, alt ekstremitede başlayan ve zamanla üst ekstremitelere ilerleyen, "eldiven ve çorap" tarzında görülen distal simetrik polinöropatidir (5). DNP insidansı Tip 2 DM (T2DM) hastalarında yllda 6100/100.000, Tip 1 DM (T1DM) de ise 2800/100.000 iken, prevalansı T2DM'de (\%8-51) T1DM'de (\%11-50) civarındadır (6). Hastaların \%60-70'inde diyabete, vücudun tüm organlarını etkileyebilen nöropatiler eşlik eder ve bu komplikasyonlar T2DM hastaları için önemli morbidite ve mortalite nedenidir. Bu ciddi derecede yüksek insidanstan dolayı günümüzde Amerika Birleşik Devletleri'nde diyabetik nöropatinin ylllk maliyeti 10 milyar dolardan fazladır (7). Hiperglisemi ve dislipidemi, glukoz ve lipid metabolizmasında, nöronal fonksiyonu etkileyebilecek çeşitli patolojik değişikliklere yol açar. Reaktif oksijen türlerinin (ROS) üretimi ile diyabetik nöropati gelişimine katkıda bulunur. Aynı zamanda hiperglisemi gelişmiş glikasyon son ürünlerinin (AGEs) üretimine yol açar. Diyabet süresi ve HbA1c düzeyleri diyabetik nöropati için majör prediktörlerdendir. Obezite, sigara, alkol kullanımı nöropati gelişmesi için diğer risk faktörleridir (8). HbAlc seviyelerinden bağımsız, metabolik sendrom bileșenlerinin sayısı, örneğin hipertrigliseridemi, hipertansiyon, abdominal obezite ve yüksek yoğunluklu lipoprotein (HDL) seviyeleri, hastalarda diyabetik nöropati ile tutarlı bir şekilde ilişkilidir (6). Diyabetik nöropatinin erken saptanması, diyabetik hastaların metabolik kontrolü ve diyabetik nöropatinin potan- siyel olarak ciddi sonuçlarının erken müdahale edilmesinde ve önlenmesinde kritik öneme sahiptir $(9,10)$. TURNEP çalışması sonuçlarına göre, kötü glisemik kontrol, diyabetik nöropati gelişimine katkıda bulunmaktadır ve klinik muayene ile belirlenen diyabetik periferik nöropatinin, diyabetli hastaların \%40,4'ünü etkilediği, klinik muayeneye sinir iletim çalışmaları eklenilirse bu oranın $\% 62,2$ 'ye yükseldiği gösterilmiştir (11). Biz bu çalışmamızda, rutin İç Hastalıkları ve Fizik Tedavi ve Rehabilitasyon (FTR) Polikliniğinde DM tanılı hastaların hangilerinde mutlak surette diyabetik nöropati varlığının akla getirilmesi ve bu tanı üzerinde durulmasını incelemek istedik.

\section{GEREÇ ve YÖNTEMLER}

Çalışmaya 2018-2019 yılları arasında Karabük Üniversitesi Eğitim ve Araştırma Hastanesi Fiziksel Tıp ve Rehabilitasyon (FTR) ve İç Hastalıkları polikliniğine başvuran DM tanılı 399 hasta dahil edildi. Hastaların demografik verileri, $\mathrm{HbA1c}$ değerleri, hastalık süreleri, hastalığa bağlı kullandığı ilaçlar, diyabetik polinöropatisi olup olmadığı ve eğer varsa kullandığ 1 tedaviler geriye dönük olarak tarand 1 ve kaydedildi. Hastaların polinöropati tanıları LANSS ölçeği kullanılarak değerlendirildi. Hastalar DNP olup olmadıkları ve obez olup olmadıklarına göre gruplara ayrıldı. Vücut kütle indeksi (VKI) $\geq 30 \mathrm{~kg} / \mathrm{m}^{2}$ olanlar obez olarak kabul edildi. Çalışmaya katılan tüm hastalardan imzalı aydınlatılmış gönüllü onam formu alındı ve bu çalışma için Karabük Üniversitesi Etik Kurulundan 11/11/2019 tarihinde 77192459-050.99-E.11987 numaralı etik onay alındı.

İstatistiksel yöntem olarak, verilerin normal dağılip dağılmadığının belirlenmesi için Kolmogrov Smirnov testi kullanıldı. Normal dağılan verilerin karşılaştırılması için Student $\mathrm{t}$ testi, korelasyonu için Pearson korelasyon testi kullanıldı. Bağımsız risk faktörlerini belirlemek için çok değişkenli lojistik regresyon analizi kullanıldı. Kategorik verilerin arasındaki ilişkiyi belirlemek amaçlı ki kare testi kullanıldı. p<0,05 anlamlı olarak kabul edildi. 


\section{BULGULAR}

Çalışmaya 173 erkek, 226 kadın olmak üzere toplam 399 hasta dahil edildi. Hastaların yaş ortalaması $60,5 \pm$ 12,0 yıl olarak saptandı. DM tanı sonrası geçen süre 61,2 $\pm 29,2$ aydı. HbA1c değeri ortalaması ise $\% 8,3 \pm 1,9$ idi. Hastaların \%95,2'si oral antidiyabetik (OAD) tedavi alırken, $\% 50,9$ 'u insülin tedavisi altındayd. Obezite oranı $\% 61,9$ olarak saptandı. Diyabetik polinöropati \%38,6 oranında hastada tespit edildi (Tablo 1). DNP saptanan hastaların kullandığ kullandığı, \%37'sinin pregabalin, \%26'sının gabapentin ve $\% 7,8$ 'inin duloksetin kullandığg görüldü. Pregabalinin ortanca dozunun $150 \mathrm{mg}$ (50-600 $\mathrm{mg} /$ gün peroral) olduğu, gabapentinin ortanca dozunun 1200 gram (200$2400 \mathrm{mg} /$ gün peroral) olduğu saptandı. Hastaların yaşı ile hastalık süreleri arasında zayıf şiddette pozitif korelasyon saptanırken $(\mathrm{r}=0,101, \mathrm{p}=0,036)$, HbAlc düzeyleri ile de yine zayıf şiddette negatif korelasyon saptandı $(\mathrm{r}=-0,106$, $\mathrm{p}=0,034)$. Pregabalin ya da gabapentin dozları ile yaş, HbAlc ya da hastalık süreleri arasında anlamlı ilişki mevcut değildi $(\mathrm{p}>0,05)$. Ortalama yaş, VKİ ve $\mathrm{DM}$ süresi $\mathrm{DNP}+$ grupta DNP- gruba kıyasla anlamlı derecede yüksekti [sırasıyla; $(62,4 \pm 11,1$ ve $59,3 \pm 12,4$ yll, $p=0,014),(33,6 \pm 6,3$ ve $\left.31,3 \pm 6,5 \mathrm{~kg} / \mathrm{m}^{2}, \mathrm{p}=0,001\right)$ ve $(72,7 \pm 29,9$ ve $54,0 \pm 26,5$ ay, $\mathrm{p}<0,001)$ ]. DNP HbA1c değeri $>\% 7,0$ olanlarda $\leq \% 7,0$ olanlara göre ve $\mathrm{VKI} \geq 30 \mathrm{~kg} / \mathrm{m}^{2}$ olanlarda $<30 \mathrm{~kg} / \mathrm{m}^{2}$ olanlara göre daha sık görülmekteydi ( $\mathrm{p}=0,026$ ve $\mathrm{p}=0,021)$. OAD, insülin kullanımları ve HbA1c düzeyleri gruplar arasında benzerdi ( $p=0,107, p=0,075$ ve 0,232 ). Lojistik regresyon analizinde, HbAlc düzeyi, cinsiyet ve insülin ya da oral antidiyabetik kullanımları ile DNP arasında bağımsız bir ilişki saptanmazken $(P>0,05)$, hastalık süresinin uzun (>61 ay) olması, ileri yaş ve obezitenin DNP için bağımsız prediktörler oldukları saptandı [sırasıyla; Odds ratio (OR): 2,78 (\%95 Güven Aralığ (CI); 1,832 - 4,228, p<0.001), OR: 1,62, \%95CI; $1,053-2,493), \mathrm{P}=0,028$ ve OR: $1,78, \% 95 \mathrm{CI}$; 1,143 - 2,789), $\mathrm{P}=0,011$ )] (Tablo 2).

\section{TARTIŞMA}

Diyabetik periferik nöropatinin erken belirtileri ince liflerin tutulumu ile gelişir ve ağrı, yanma ile karıncalanma gibi disestezik yakınmaları içerir. Kalın liflerin tutulumu, uyuşukluğa ve duyu kaybına neden olur (12). Duyu kaybı, distal sensorimotor polinöropatinin varlığını gösterir ve diyabetik ayak gelişimi için bir risk faktörüdür $(13,14)$. Diyabet süresi ve glisemik kontrolün derecesi insidans ve ciddiyeti etkileyen majör faktörlerdir (15). Diyabetik nöropati patogenezinde vasküler, metabolik ve immün faktörler rol oynar (16). En etkin tedavi sonuçları esasında bu hastalığı önlemekte yatmaktadır ve bunlar glikoz düzeyinin kontrolü ve ağrı tedavisidir, çünkü DNP bir kez oluştuğunda çoğunlukla kalıcı ve ilerleyici seyirlidir (17). Literatürde diyabetik polinöropatiyi predikte eden klinik parametreler; uzun hastalık süresi, kötü glisemik kontrol ve ileri yaş olduğuna dair yayınlar mevcuttur. Bizim çalışmamızda da, uzun hastalık süresi ( $>5$ yıl), obezitenin (VKI $\geq 30)$ ve ileri yaş (>61 yaş) diyabetik polinöropatinin

Tablo 1: Hastaların demografik özelliklerinin polinöropati durumuna göre karşılaştırılması.

\begin{tabular}{|c|c|c|c|}
\hline Değişkenler & Polinöropatik $(n=154)$ & Polinöropatik olmayan $(n=245)$ & $\mathbf{P}$ \\
\hline Yaş (yıl \pm SS) & $62,4 \pm 11,1$ & $59,3 \pm 12,4$ & 0,014 \\
\hline \multicolumn{4}{|l|}{ Cinsiyet } \\
\hline Kadın & $95(61,7)$ & $131(53,4)$ & \\
\hline Erkek & $59(38,3)$ & $114(46,6)$ & 0,103 \\
\hline $\mathrm{HbA1c}(\% \pm \mathrm{SS})$ & $8,53 \pm 1,89$ & $8,29 \pm 1,91$ & 0,232 \\
\hline DM Süresi $(\mathrm{Ay} \pm \mathrm{SS})$ & $72,73 \pm 29,91$ & $54,04 \pm 26,53$ & $<0,001$ \\
\hline \multicolumn{4}{|l|}{ OAD kullanımı } \\
\hline Var & $150(97,4)$ & $230(93,8)$ & 0,107 \\
\hline Yok & $4(2,6)$ & $15(6,29)$ & \\
\hline \multicolumn{4}{|l|}{ İnsülin kullanımı } \\
\hline Var & $87(56,4)$ & $116(47,3)$ & 0,075 \\
\hline Yok & $67(43,6)$ & $129(52,7)$ & \\
\hline VKİ $\left(\mathrm{Kg} / \mathrm{m}^{2} \pm \mathrm{SS}\right)$ & $33,6 \pm 6,3$ & $31,3 \pm 6,5$ & 0,001 \\
\hline \multicolumn{4}{|l|}{ Obezite } \\
\hline Var & $109(70,8)$ & $138(56,3)$ & 0,002 \\
\hline Yok & $45(29,2)$ & $107(43,7)$ & \\
\hline
\end{tabular}

SS: standart sapma, OAD: Oral antidiyabetik, VKİ: Vücut kütle indeksi. 
Tablo 2: Diyabetik polinöropatiyi predikte eden bağımsız faktörler için lojistik regresyon analizi.

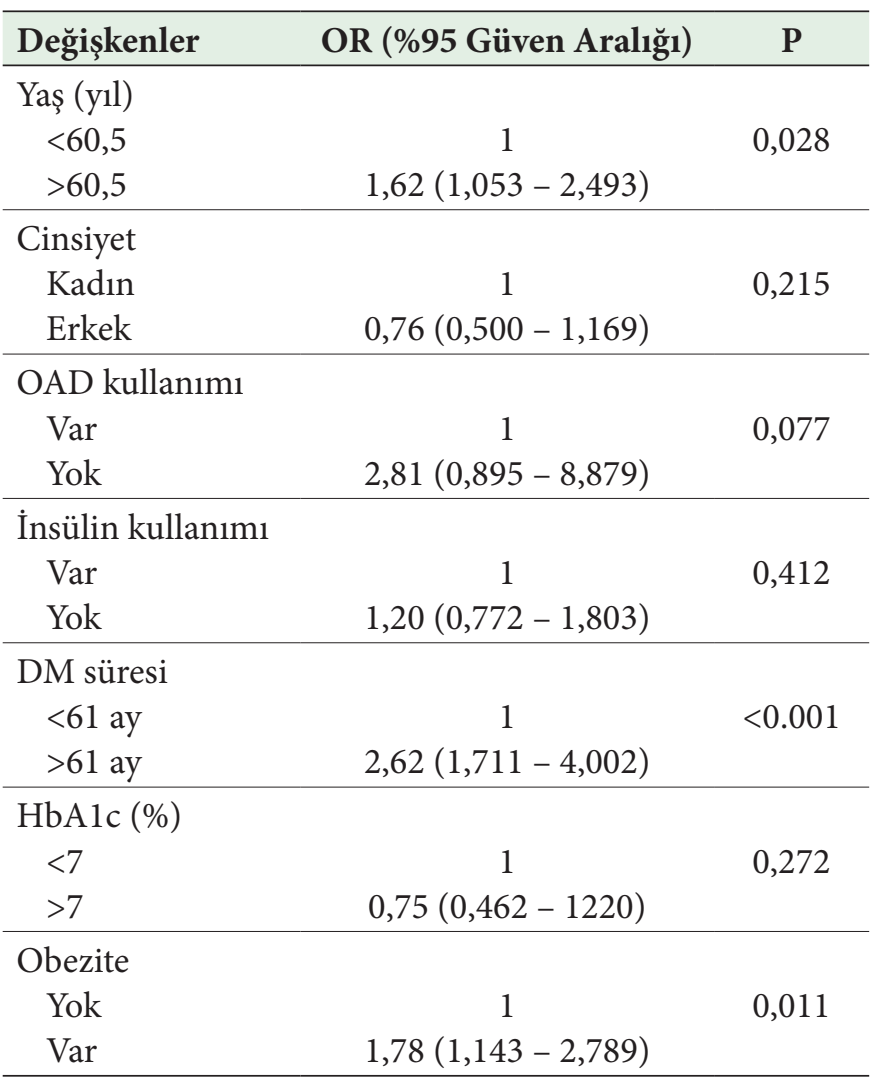

OR: Odds ratio; DM: Diabetes mellitus; OAD: Oral antidiyabetik.

bağımsız prediktörleri olduğu bulunmuștur. Meta analiz verilerine göre de bulgularımız oldukça tutarlıdır (18). Obezitenin de DNP için bağımsız bir prediktör olması da yine önemli ve literatürle tutarlı bir bulgudur. Obezlerde DNP sıklığının artmasındaki en önemli nedenler, obezitenin kötü glisemik kontrol (19), artmış oksidatif stres, yüksek sitokin düzeyleri (özellikle TNF-a) (20) ve buna bağlı nöronal hasar ve idiyopatik nedenler (21) olarak sıralanabilir. Ancak bulgularımıza göre kötü glisemik kontrolü gösteren yüksek HbAlc değerlerinin diyabetik polinöropati ile ilişkisi saptanamamıştır. Bunun bir sebebi, genel hasta grubumuzun glisemik kontrol düzeylerinin beklenildiğinden kötü olması olabilir. Bu durumun bir diğer nedeni; DM'li hastalarda polinöropatinin, kötü glisemik kontrolden ziyade, bu kötü glisemik düzeylerin ne kadar sürdüğü ile daha bağıntılı olabileceğidir. Çünkü yapılan histopatolojik çalışmalarda da görülmüștür ki, diyabetik polinöropati akut ya da subakut olmaktan ziyade, daha çok kronik inflamasyonun da eşlik ettiği ve oldukça yavaş ilerleyen bir süreçtir $(22,23)$.

İyi bir glisemik kontrolün özellikle T1DM'lerde diyabetik nöropati gelişmesine karşı koruyuculuğu daha belirgin olsa da bu etki T2DM'lerde minimaldir ve bu nedenle uzun etkili yeni antidiyabetikler ve yeni nesil insülin preparatları geliştirilmeye devam etmektedir (24). Diyabetli hastalarda yaşam tarzı değişikliği ile sinir lif yoğunluğunda artış gösterilmiş olsa da nöropati gelişimini nasıl engelleyebildiği hâlâ belirsizliğini korumaktadır. Diyabetik nöropati diyabetin mikrovasküler komplikasyonları arasında spesifik bir tedavisi olmayan tek komplikasyonudur. Diyabette komplikasyon oluşumunun önlenmesi ya da erken tespit edilmesi hastalığın ilerlemesini geciktirir ve yaşam kalitesini iyileştirerek yaşam süresini uzatır.

Çalışmamızdaki bulgulara göre diyabetes mellituslu hastalarda beş yıldan uzun hastalık süresi, ileri yaş ve obezitenin diyabetik polinöropati için bağımsız klinik parametreler oldukları saptanmıştır. İç Hastalıkları ve FTR polikliniğinde diyabetik polinöropatiyi predikte edebilen bu kriterler ucuz ve kolay uygulanabilirliği nedeniyle göz önünde tutulmalıdır.

Teșekkür

Katkılarından dolayı Doç. Dr. Fatih Karataş’a teşekkür ederiz.

Finansal Destek

Çalışmada herhangi bir finansal destek yoktur.

Çıkar Çatışması

Yazarlar arasında herhangi bir çıkar çatışması yoktur.

Yazarların Makaleye Katkı Beyanı

Fikir: Hatice Gülşah Karataş, Ayşegül Ertınmaz Özkan, Tasarım: Hatice Gülşah Karataş, Denetim: Ayşegül Ertınmaz Özkan, Kaynaklar: Hatice Gülşah Karataş, Malzemeler: Ayşegül Ertınmaz Özkan, Veri toplanması ve/veya işlemesi: Hatice Gülşah Karataş, Analiz ve/veya yorum: Hatice Gülşah Karataş, Literatür taraması: Hatice Gülşah Karataş, Yazı yazma: Hatice Gülşah Karataş, Ayşegül Ertınmaz Özkan, Eleştirel inceleme: Hatice Gülşah Karataş.

\section{KAYNAKLAR}

1. Eryigit Erogul L, Erogul O. Prevalence of diabetes mellitus in patients with pterygium. Eurasian J Med Invest. 2018;2(2):8082.

2. Cho NH, Shaw JE, et al. IDF Diabetes Atlas: Global estimates of diabetes prevalence for 2017 and projections for 2045. Diabetes Res Clin Pract. 2018;138:271-281.

3. Zheng Y, Ley SH, et al. Global aetiology and epidemiology of type 2 diabetes mellitus and its complications. Nat Rev Endocrinol. 2018;14(2):88-98.

4. Tecilazich F, Veves A. Role of peripheral neuropathy in the development of foot ulceration and impaired wound healing in diabetes mellitus, in Nutritional and Therapeutic Interventions for Diabetes and Metabolic Syndrome. Elsevier. 2018, p.95-104. 
5. Almuhannadi H, Ponirakis G, et al. Diabetic neuropathy and painful diabetic neuropathy: Cinderella complications in South East Asia. J Pak Med Assoc. 2018;68(1):85-89.

6. Feldman EL, Callaghan BC, et al. Diabetic neuropathy. Nat Rev Dis Primers. 2019;5(1):1-18.

7. Care D. Economic costs of diabetes in the US in 2017. Diabetes Care. 2018;41:917-928.

8. Yagihashi S, Mizukami H. Diabetic Neuropathy, in Diabetes and Aging-Related Complications. Springer, 2018, p.31-43.

9. Tesfaye S, Boulton AJ, et al; Toronto Diabetic Neuropathy Expert Group. Diabetic neuropathies: Update on definitions, diagnostic criteria, estimation of severity, and treatments. Diabetes Care. 2010;33(10):2285-2293.

10. Polat M, Akyer UO. Pneumonia in patients with diabetes mellitus: A single-center experience. Eurasian Journal of Medicine and Oncology. 2017;1(1):14-18.

11. Erbas T, Ertas M, et al; TURNEP Study Group. Prevalence of peripheral neuropathy and painful peripheral neuropathy in Turkish diabetic patients. J Clin Neurophysiol. 2011;28(1):5155.

12. Ametov AS, Barinov A, et al; SYDNEY Trial Study Group. The sensory symptoms of diabetic polyneuropathy are improved with $\alpha$-lipoic acid: the SYDNEY trial. Diabetes Care. 2003;26(3):770-776.

13. Määttä LL, Charles M, et al. Prospective study of neuropathic symptoms preceding clinically diagnosed diabetic polyneuropathy: ADDITION-Denmark. Diabetes Care. 2019;42(12):2282-2289.

14. Gylfadottir SS, Weeracharoenkul D, et al. Painful and nonpainful diabetic polyneuropathy: Clinical characteristics and diagnostic issues. J Diabetes Investig. 2019;10(5):1148-1157.
15. Dyck PJ, Davies JL, et al. Risk factors for severity of diabetic polyneuropathy: Intensive longitudinal assessment of the Rochester Diabetic Neuropathy Study cohort. Diabetes Care. 1999 Sep;22(9):1479-1486.

16. Burns TM, Mauermann ML. The evaluation of polyneuropathies. Neurology. 2011;76:S6-13.

17. Podwall D, Gooch C. Diabetic neuropathy: Clinical features, etiology, and therapy. Curr Neurol Neurosci Rep. 2004;4(1):5561.

18. Sobhani S, Asayesh H, et al. Prevalence of diabetic peripheral neuropathy in Iran: A systematic review and meta-analysis. J Diabetes Metab Disord. 2014;13(1):97.

19. Ziegler D, Nowak H, et al. Treatment of symptomatic diabetic polyneuropathy with the antioxidant $\alpha$-lipoic acid: A metaanalysis. Diabet Med. 2004;21(2):114-121.

20.Satoh J, Yagihashi S, et al. The possible role of tumor necrosis factor- $\alpha$ in diabetic polyneuropathy. Exp Diabesity Res. 2003;4(2):65-71.

21. Ziegler D, Rathmann W, et al; KORA Study Group. Prevalence of polyneuropathy in pre-diabetes and diabetes is associated with abdominal obesity and macroangiopathy: The MONICA/KORA Augsburg Surveys S2 and S3. Diabetes Care. 2008;31(3):464-469.

22. Dyck PJ, Giannini C. Pathologic alterations in the diabetic neuropathies of humans: A review. J Neuropathol Exp Neurol. 1996;55(12):1181-1193.

23. Yagihashi S. Pathology and pathogenetic mechanisms of diabetic neuropathy. Diabetes Metab Rev. 1995;11(3):193-225.

24. Karatas F, Sahin S, et al. The highest (3600 IU) reported overdose of insulin glargine ever and management. Indian J Crit Care Med. 2015;19(12):750-751. 